\title{
Folate deficiency-triggered redox pathways confer drug resistance in hepatocellular carcinoma
}

\author{
Chun-Te Ho ${ }^{1, *}$, Hung-Sheng Shang ${ }^{2, *}$, Jin-Biou Chang ${ }^{2, *}$, Jun-Jen Liu ${ }^{3}$, Tsan-Zon Liu ${ }^{4}$ \\ ${ }^{1}$ Graduate Institute of Medical Sciences, College of Medicine, Taipei Medical University, Taipei, Taiwan \\ ${ }^{2}$ Department of Pathology, National Defense Medical Center, Division of Clinical Pathology, Tri-Service General Hospital, \\ Taipei, Taiwan \\ ${ }^{3}$ School of Medical Laboratory Science and Biotechnology, Taipei Medical University, Taipei, Taiwan \\ ${ }^{4}$ Translational Research Laboratory, Cancer Center, Taipei Medical University and Hospital, Taipei, Taiwan \\ *These authors have contributed equally to this work
}

Correspondence to:

Tsan-Zon Liu, e-mail: tzliu@tmuh.org.tw

Jun-Jen Liu, e-mail: jjliu_96@tmu.edu.tw

Keywords: chemotherapy, folate, GRP78, multi-drug resistance, hepatoma

Received: February 22, $2015 \quad$ Accepted: June 17, $2015 \quad$ Published: June 27, 2015

\section{ABSTRACT}

Patients with hepatocellular carcinoma (HCC) are prone to folate deficiency (FD). Here we showed that, in cell line-specific manner, FD caused resistance to FD-induced oxidative stress and multi-drug resistance (MDR). This resistance was due to upregulation of glucose-regulated protein 78 (GRP78) and Survivin. Using siRNA and Epigallocatechin gallate (EGCG), we found that GRP78 and Survivin cooperatively conferred MDR by decreasing FD-induced ROS generation. Our data showed that FD increases GRP78 and Survivin, which serve as ROS inhibitors, causing MDR in HCC. We suggest that folate supplementation may enhance the efficacy of chemotherapy.

\section{INTRODUCTION}

Folic acid (folate; vitamin B9) is an essential micronutrient and a critical coenzymes for the de novo synthesis of purine and thymidylate nucleotides and methylation and demethylation of homocysteine/methionine [1-3]. Folate receptor overexpressed in tumor tissues and disruption of one-carbon metabolism can cause oxidative stress-mediated DNA damage and apoptosis [4-9].

Hepatocellular carcinoma (HCC) is one of the leading cause of death [10], with low response to conventional chemotherapies [11, 12]. Most HCC patients are prone to folate deficiency [13-15]. Meenam et al. [16] observed that folate content was lower in tumors than the adjacent normal cells. Furthermore, dietary methyl deficiency and Hcy-aggravated hydrogen peroxide production have been demonstrated to be a pair of contributing factors in promoting mutagenesis and hepatocarcinogenesis $[17,18]$. Importantly, Kuo et al. [15] reported that approximately $60 \%$ of HCC patients were deficient in folate and established that folate levels decreased drastically as HCC stage progressed. Thus, they suggested that low blood folate status could be a risk factor for tumor progression. These studies established that folate deprivation is a risk factor for HCC.

Nutritional deficiencies, such as folate deprivation, and chemotherapeutic drugs can cause cell death via generation of oxidative-nitrosative stress (ONS) [19-22]. However, some types of cancer cells exhibit increased reactive oxygen species (ROS) generation that may promote cell proliferation and in many cases can be coupled to redox adaptation (RA) to promote cell survival and drug resistance. RA can explain how cancer cells survive under persistent endogenous ROS stress and become resistant to certain anti-cancer agents. Thus far, research efforts focusing on whether or not folate deficiency (FD)-induced ONS on the induction of RA and its potential impacts on the MDR acquisition of HCC cells have been relatively sparse. Our data demonstrated that some poorly-differentiated and invasive subclone variant, such as SK-Hep-1 cells, could withstand FD-induced ONS via evading apoptosis and becoming MDR through RA-mediated upregulation of GRP78 and Survivin, which decrease oxidative stress and promote survival. 


\section{RESULTS}

Folate deficiency (FD) can transform redox adaptation-prone hepatoma cell lines into MDR phenotype

A group of HCC subclone variants including Hep G2, Hep J5, Mahlavu and SK-Hep-1 were cultivated under either FC or FD condition for one-week, followed by the treatment of these cells with various concentrations of a group of ROS-producing anti-cancer drugs including sorafenib, cisplatin, paclitaxel and doxorubicin. As judged by the viability data, except for Hep G2 cells (redox adaptation-null; Supplementary Figure 1), all three other HCC cell types cultivated under FD condition could unilaterally transform themselves into MDR phenotype. However, this acquired MDR attribute could apparently be restituted either partially or even completely by folate resupplementation (FR) (Figure 1). This finding implies that folate micronutrient per se can confer the cells with the capacity to reverse MDR acquisition. ${ }^{*} p<0.05$; ${ }^{* *} p<0.01 ; * * * p<0.001$.

\section{FD-evoked MDR acquisition is linked to the redox adaptation (RA)-mediated upregulation of GRP78 and Survivin}

Cultivation of SK-Hep-1 cells under FD condition could trigger the upregulation of ER stress chaperone protein 78 (GRP-78) expression. The underlying mechanism associated with this observed phenomenon was demonstrated to be mechanistically linked to the increased cleavage of ATF- $6 \alpha(90 \mathrm{kDa})$ transcription factor to its active subunits $(50 \mathrm{kDa})$ and nuclear translocation to release GRP-78 from its conjugated complex (Figure 2B). Along this same vein, FD condition could also capacitate SK-Hep-1 cells to upregulate Survivin expression which in turn can cooperatively act as the inhibitors for caspase 3 expression (Figure 2C). The functional attribute of overexpressed GRP78 was demonstrated to serve as a ROS sinker which alleviated the ROS production to evade apoptotic lethality as reflected by flowcytometric data using DCF-DA as the probe (Figure 2D).

\section{GRP78 silencing of SK-Hep-1 cells alleviates MDR}

To further confirm that GRP78 is a genuine chemoresistant effector, SK-Hep-1 cells were grown under FD condition for one-week in order to allow GRP78 induction. Subsequently, GRP78 thus induced was allowed to be knockdowned (KD) by lentivirus-mediated knockdown technique. The scramble and two types of GRP78 KD cells were then treated with a group of anti-cancer drugs including sorafenib, cisplatin, paclitaxel and doxorubicin. Our results indicate that without exception, all the drug-treated GRP78 KD cells were substantially more susceptible to be eradicated by these drugs as compared to scramble cells (Figure 3). These data unequivocally demonstrate that GRP78 per se is a legitimate chemoresistant effector. $* * p<0.01 ; * * * p<0.001$.

\section{Direct targeting of either forcedly expressed or constitutively endowed GRP78 with EGCG effectively improves the eradicating efficiency of HCC cells}

In order to evaluate the effectiveness of direct targeting of GRP78 with its binder EGCG for the eradicating efficiency, several types of experiments were performed. First, we purposely grew SK-Hep-1 cells under FD condition to allow these cells to overexpress GRP78. Subsequently, these cells were treated with various concentrations of EGCG and continued to cultivate for an additional three days. Our data clearly demonstrated that only GRP78-overexpressing SK-Hep-1 cells (forcedly expressed subline) were particularly sensitive to be eradicated by EGCG treatment (Figure 4A). To confirm this applicability, we then tested the effect of EGCG on HCC Mahlavu cells genetically endowed with overexpressed GRP78. Again, a similar effect of EGCG could be reproduced (Figure 4B). ${ }^{* *} p<0.01$; $* * * p<0.001$.

\section{Constitutively overexpressed GRP78 efficaciously confers MDR attribute}

Two HCC subclone variants representing GRP78-overexpressing (Mahlavu and Hep J5) sublines and its non-expressing counterpart (SK-Hep-1) were used to compare their sensitivities toward a group of anti-cancer drugs including sorafenib, 5-fluorouracil (5-FU), and doxorubicin. Our data indicated that GRP78-overexpressing subclones were substantially more resistant to these drugs as compared to their non-expressing SK-Hep-1 cells (Figure 5). This finding implied that constitutively overexpressed GRP78 was also a contributing factor for the MDR acquisition. ${ }^{* *} p<0.01$; $* * * p<0.001$.

\section{Either GRP78 or survivin silencing discloses two types of drug resistance mechanisms}

To delineate the role of either GRP78 or Survivin in the process of MDR acquisition, we knockdowned (KD) GRP78 or Survivin in Mahlavu cells using siRNA interfering technique. Two distinct alterations of functional attributes of the KD cells were uncovered. First, both GRP78 and Survivin silencing 
(A)
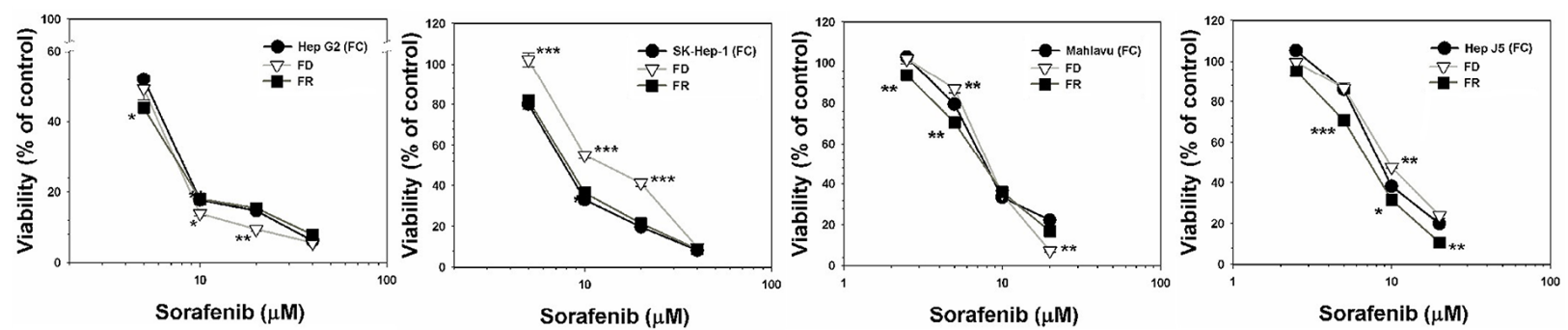

(B)
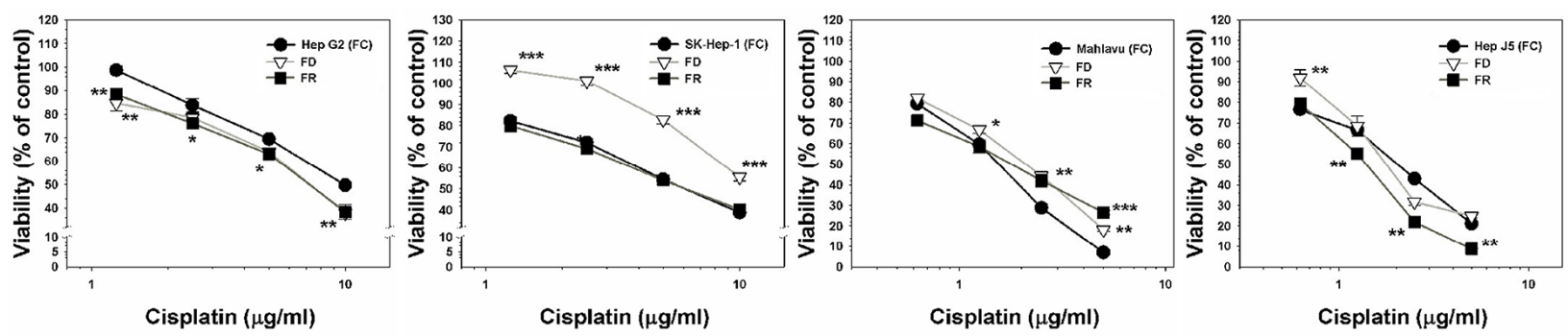

(C)
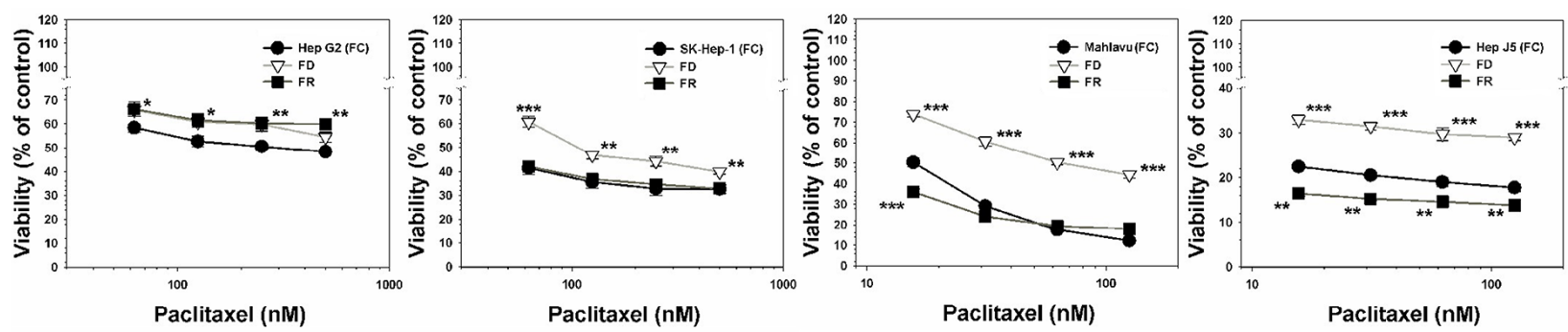

(D)
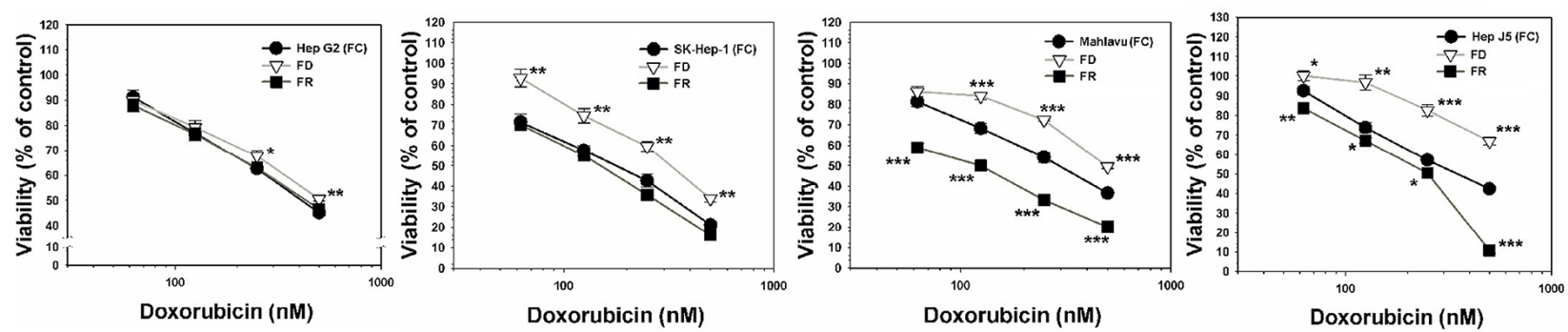

Figure 1: Comparison of relative sensitivities of a group of ROS-producing anti-cancer drugs against various HCC subclone variants cultivated in the presence or absence of folate and the effects of its resupplementation. HCC subclone variants including Hep G2, SK-Hep-1, Mahlavu and Hep J5 cells were cultivated under either folate-sufficient (FC) or folate-deficient (FD) $\alpha$-MEM media for one-week. After that, both FC and FD groups were treated with various concentrations of drugs including sorafenib A. cisplatin B. paclitaxel C. and doxorubicin D. Meanwhile, some FD cultured plates were replaced with FC medium and then similarly treated with all four drugs [designated as folate resupplemented group (FR)]. All the drug-treated cultured plates (FC, FD, and FR) were allowed to grow for additional 48-h and the viability of all cultured plates was then measured by SRB method. Remarkably, we observed that except for Hep G2 cells, all three other types of HCC cells cultivated under FD condition could transform themself into multi-drug resistant (MDR) phenotype. Even more interestingly, cells from FR group could apparently restitute themselves back to drug-sensitive attribute implying that folate micronutrient per se was capable of reversing MDR attribute. ${ }^{*} p<0.05 ; * * p<0.01 ; * * *<0.001$. 
(A)
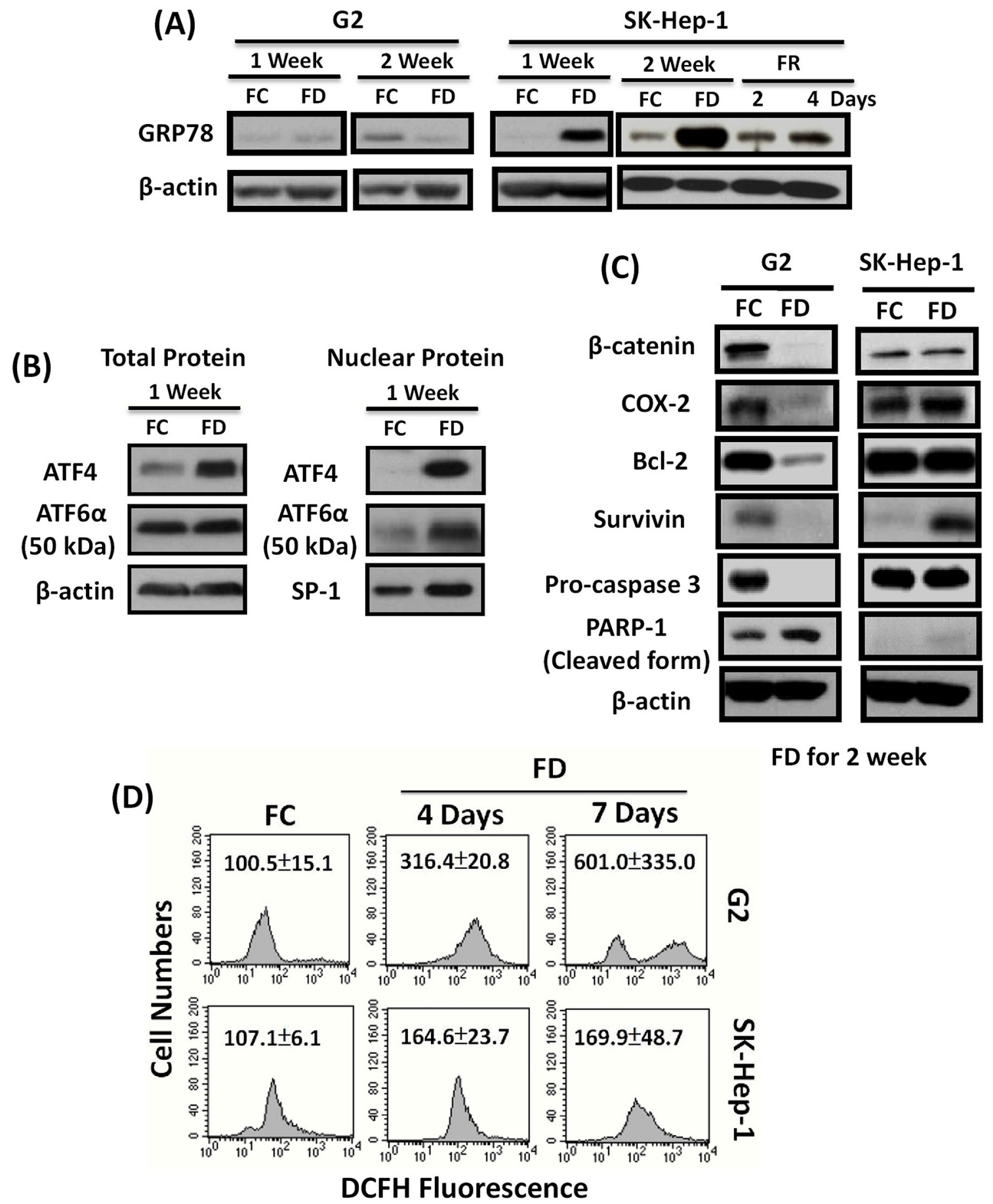

Figure 2: FD-induced multi-drug resistance (MDR) acquisition is mechanistically linked to redox adaptation (RA)-mediated upregulation of GRP78 and Survivin pathways. SK-Hep-1 and Hep G2 cells were cultivated under FC or FD condition for two-week period. Using western blot technique, we identified that SK-Hep-1, but not Hep G2 grown under FD condition could prolifically overexpressed GRP78, an ER stress chaperone protein. Interestingly, folate resupplementation could effectively downregulate GRP78 expression A. Further studies indicated that GRP78 overexpression instigated by FD was mechanistically linked to the increased cleavage of ATF-6 $\alpha(90 \mathrm{kDa})$ into active subunit ATF-6 $\alpha(50 \mathrm{kDa})$ and nuclear translocation to release GRP78 from its conjugated complex B. Additionally, FD condition could also evoke the upregulation of Survivin in SK-Hep-1, but not in Hep-G2 cells C. Both FD-induced upregulation of GRP78 and Survivin could ultimately confer resistance to apoptosis by alleviating ROS production D.

were associated with the downregulation of $\gamma-\mathrm{GCS}_{\mathrm{h}}$, a catalytic subunit of intracellular GSH biosynthesis, indicating that both effectors might influence drug resistant attribute by enhancing GSH biosynthesis (Figure 6A). Second, both GRP78 and Survivin silencing drastically increased the generation of ROS 
(A)

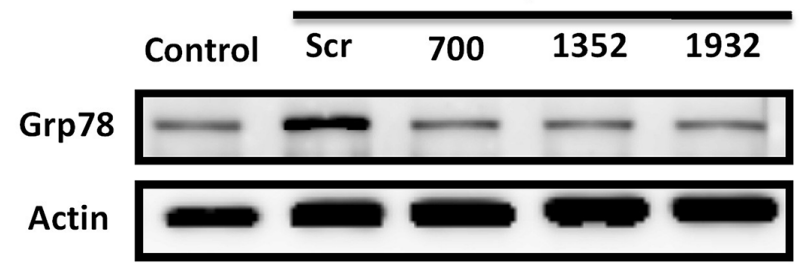

(B)

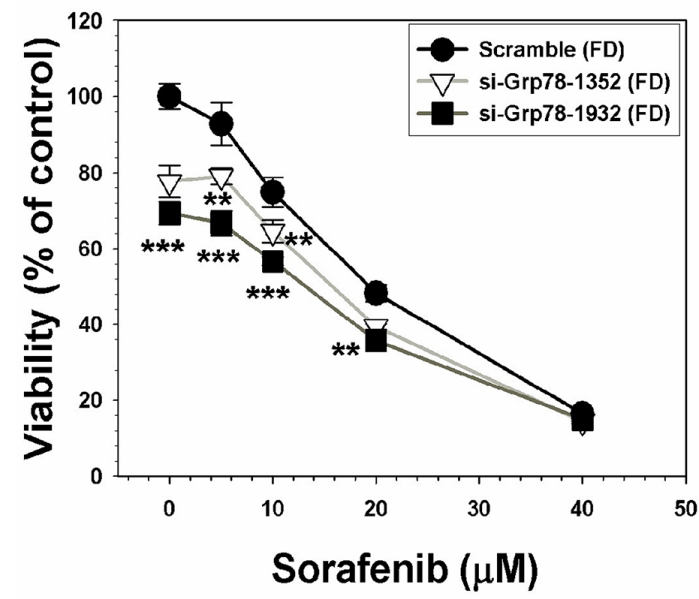

(D)

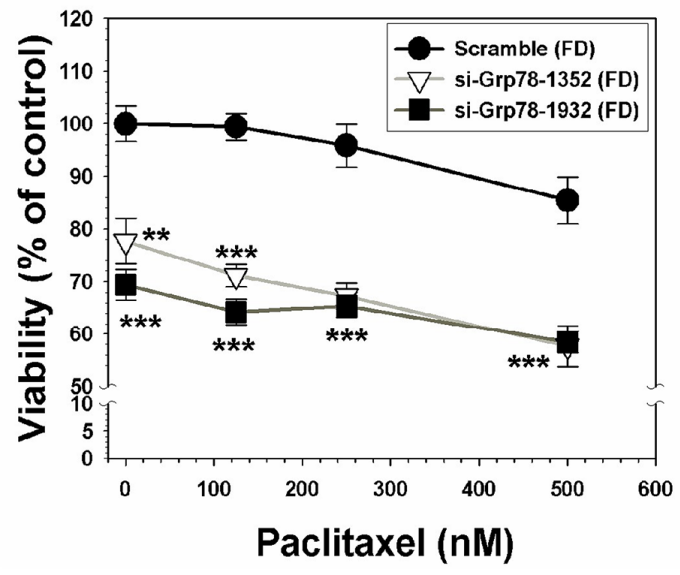

(C)

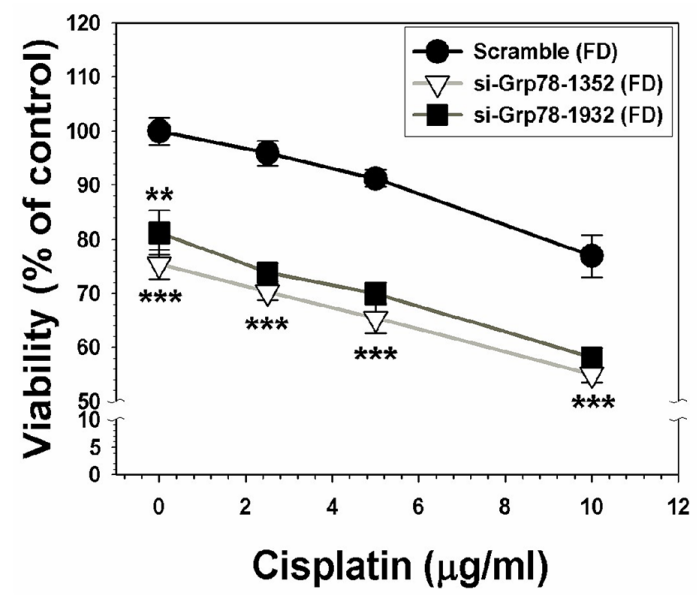

(E)

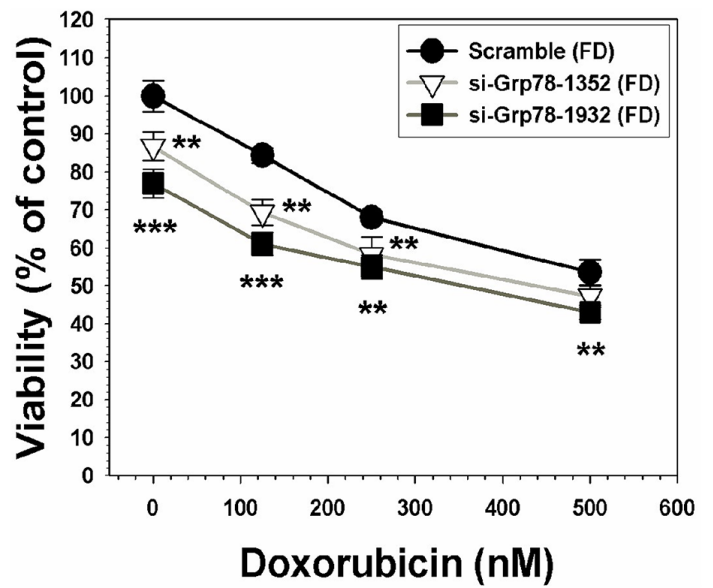

Figure 3: GRP78 silencing of SK-Hep-1 cells alleviates MDR acquisition attribute. SK-Hep-1 cells were cultivated under FD condition for one-week to allow the induction of GRP78. Subsequently, GRP78 induced by these cells were allowed to be knockdowned by siRNA technique in varying target sites that could be vividly seen from the top of Western blotting diagrams A. The scramble and GRP78 knockdown $(\mathrm{KD})$ cells were then treated with a group of anti-cancer drugs including sorafenib $\mathbf{B}$. cisplatin $\mathbf{C}$. paclitaxel $\mathbf{D}$. and doxorubicin E. with varying concentrations used as indicated. Our data indicate that without exception, all the drug-treated GRP78 KD cells were substantially more vulnerable to be eradicated as compared to scramble cells. These results clearly indicate that GRP78 per se is a genuine chemoresistant effector. ${ }^{* *} p<0.01 ; * * * p 0.001$.

during a 4-day cultivation period under FD condition implying that both effectors functioned as a ROS sinker (Figure 6B). Furthermore, both GRP78 and Survivin KD cells severely reduced their abilities to survive under FD condition (Figure 6C). Consequently, both GRP78 and Survivin KD cells were found to undergo depolarization of mitochondrial membrane potential $(\Delta \Psi \mathrm{m})$ (Figure 6D) leading to apoptotic lethality as reflected by the drastic increase of TUNEL-positive cells from $0.16 \pm 0.2$ to $98.6 \pm 0.8 \%$ (for GRP78 KD cells) and $88.07 \pm 12.85 \%$ (for Survivin KD cells), respectively (Figure 6E). 
(A)

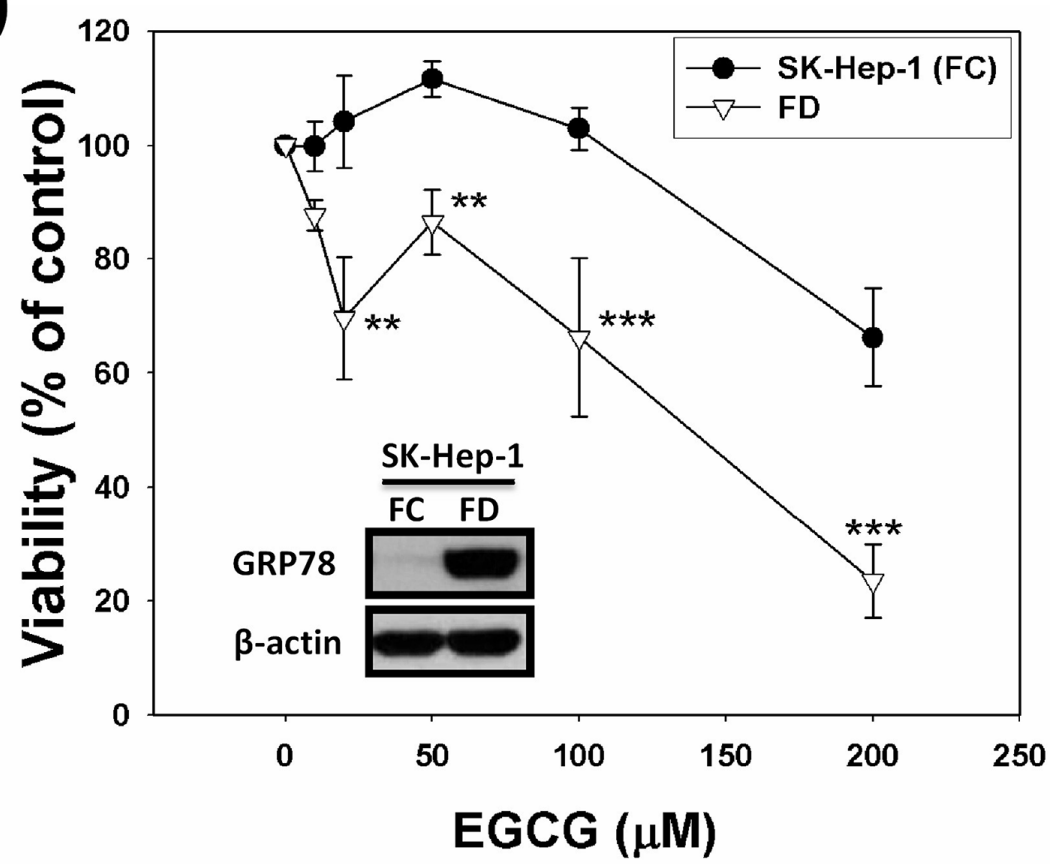

(B)

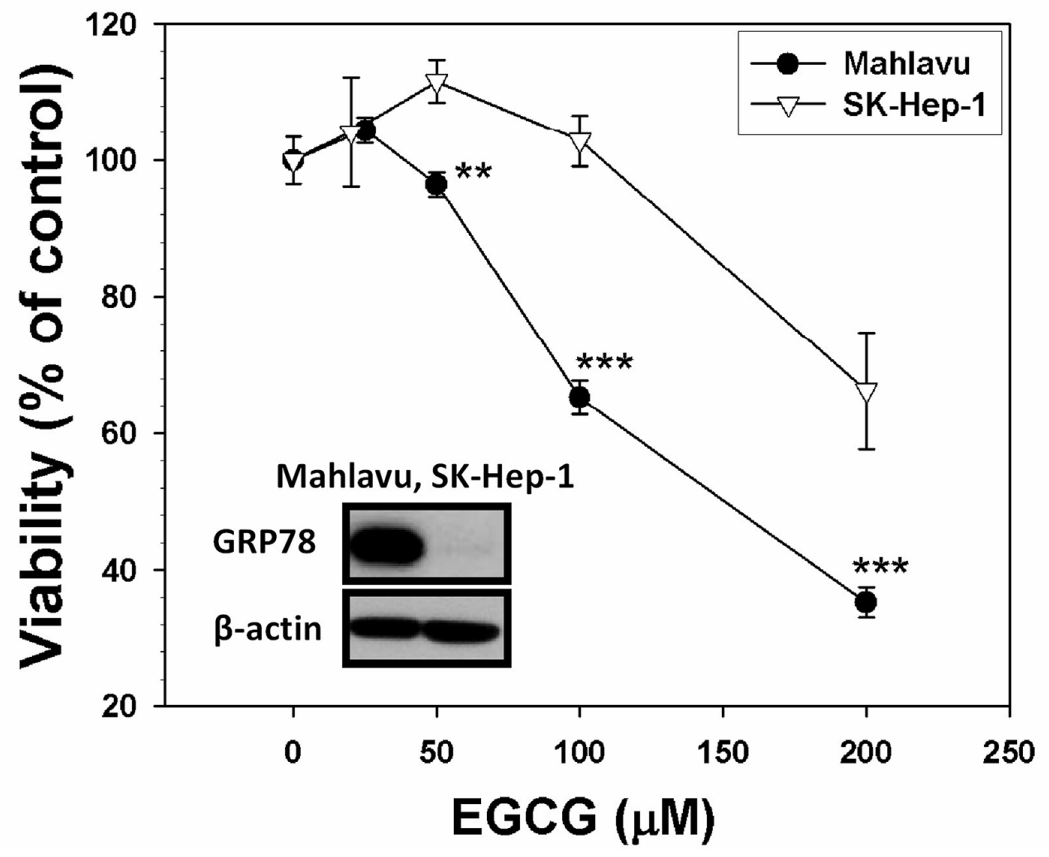

Figure 4: Direct targeting strategy using EGCG, an established binder for GRP78, veritably increases the eradicating efficiency of GRP78-expressing cells. SK-Hep-1 cells were cultivated under FD condition for 2-week to allow overexpression of GRP78 and then treated with various concentrations of EGCG. This targeting strategy improved the eradicating efficiency of GRP78-expressing SK-Hep-1 cells by EGCG. A. Similarly, Mahlavu cells, a genetically endowed GRP78-expressing subline, were shown to be equally vulnerable to EGCG-instigated eradication as compared to GRP78-non expressing SK-Hep-1 counterparts B. ${ }^{* *} p<0.01 ; * * *<0.001$.

Silencing of genetically endowed GRP78 or survivin significantly mitigates MDR acquisition attribute of Mahlavu cells

To verify if either constitutively overexpressed GRP78 or Survivin is a genuine chemoresistant effector, we used siRNA interfering technique to knockdown both effectors of Mahlavu cells. Subsequently, scramble, GRP78 KD and Survivin $\mathrm{KD}$ cells were then treated with a group of anticancer drugs including sorafenib, 5-FU, paclitaxel and doxorubicin. Our data unequivocally demonstrated 
(A)

(B)
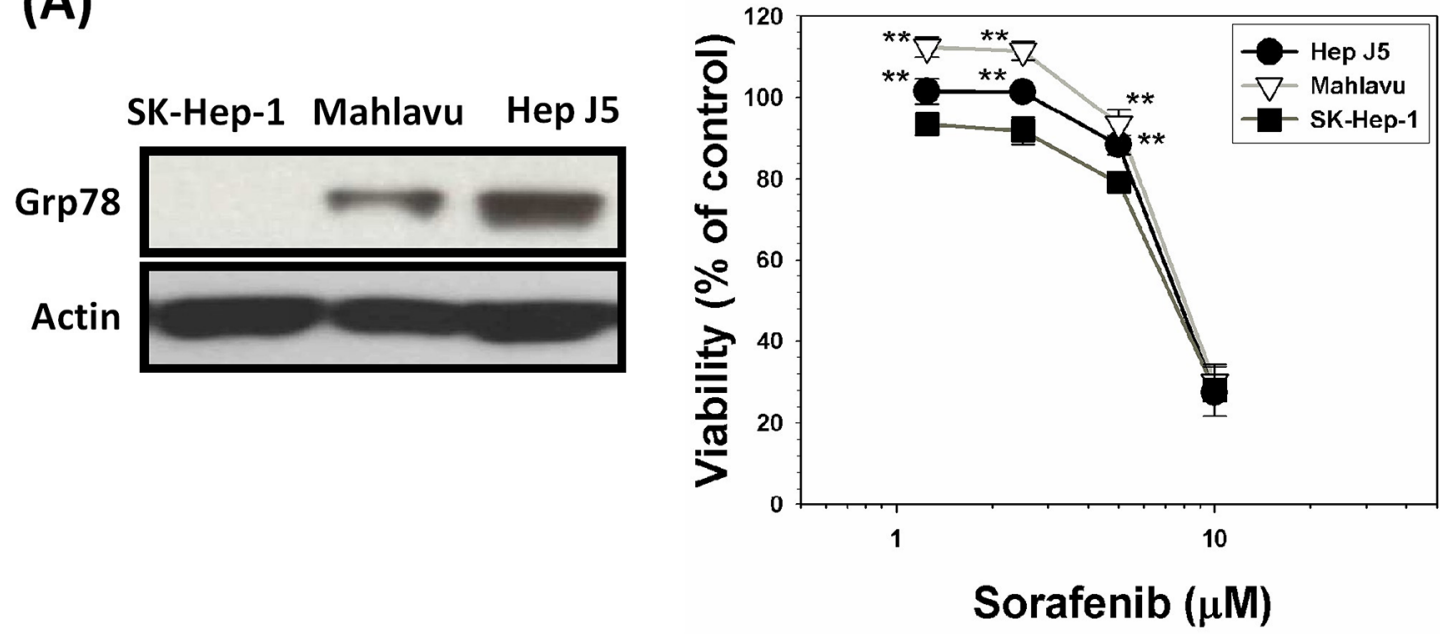

(C)

(D)
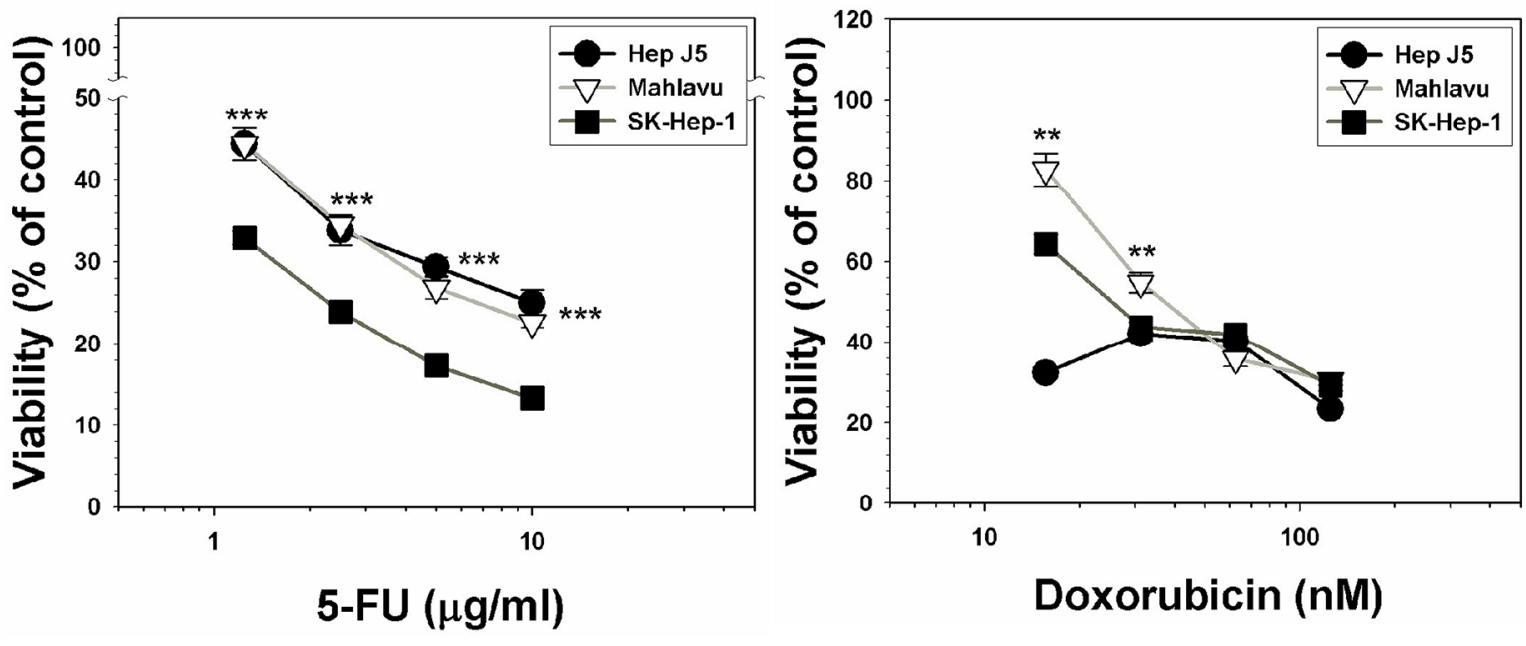

Figure 5: Constitutively overexpressed GRP78 confers stronger capacity of drug resistability. A. A group of HCC subclone variants representing GRP78-overexpressing subline (Mahlavu and Hep J5) and its non-expressing counterpart (SK-Hep-1) were used to compare for their sensitivities toward a group of anti-cancer drugs including sorafenib B. 5-fluorouracil (5-FU) C. and doxorubicin D. by SRB method. Our data indicated that GRP78-overexpressing subclones exhibited stronger capacity of resistability against all three drugs being tested as compared to their non-expressing SK-Hep-1 cells. This finding clearly implied that constitutively overexpressed GRP78 was also a contributing factor for the MDR acquisition. ${ }^{* *} p<0.01 ; * * *<0.001$.

that without exception, all the drug-treated GRP78 KD or Survivin KD cells were substantially more vulnerable to be eradicated by these drugs as compared to scramble cells (Figure 7). This finding further demonstrates that both GRP78 and Survivin are a pair of genuine chemoresistant effectors.

\section{DISCUSSION}

Cellular redox homeostasis is maintained by the balance between ROS generation and elimination.
Exogenous agents that increase ROS generation or decrease antioxidant capacity shift the redox balance in favor of an overall increase in the levels of ROS, which can ultimately induce cell death $[25,26]$. This scenario was observed in hepatoma Hep G2 cells, a well-differentiated and least oxidatively stressed subclone variant, which underwent apoptosis when exposed to folate deprivation (FD)-induced ONS, as reported previously by our group $[18,27,28]$. A similar scenario has been reported [21, 22]. However, in sharp contrast to Hep G2 cells, three HCC cell lines including SK-Hep-1, Mahlavu and Hep J5 were found to be capable of evading FD-induced apoptosis and 

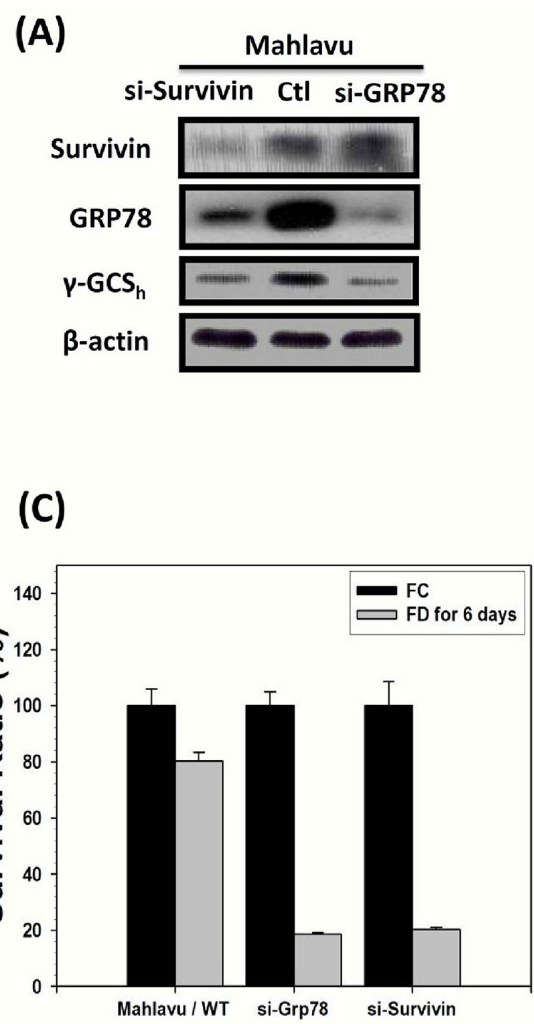

(D)

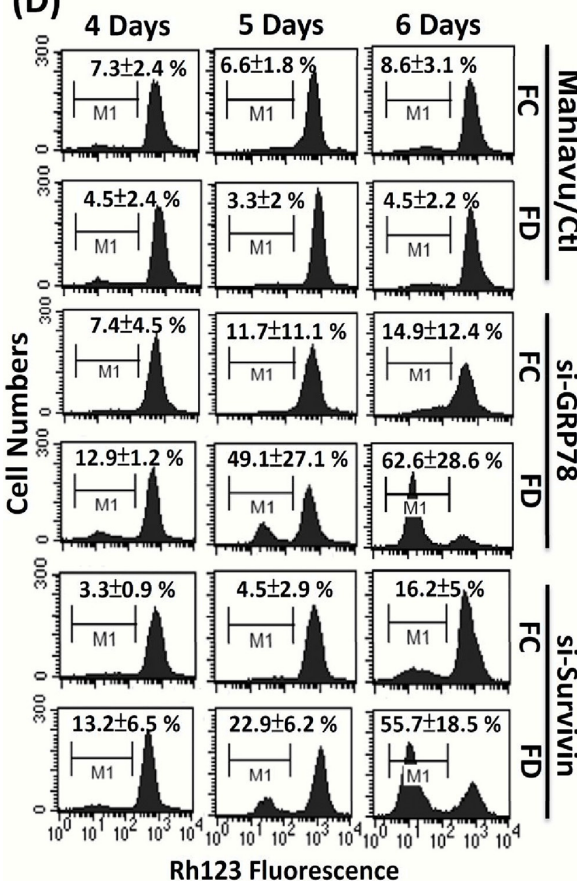

(B)
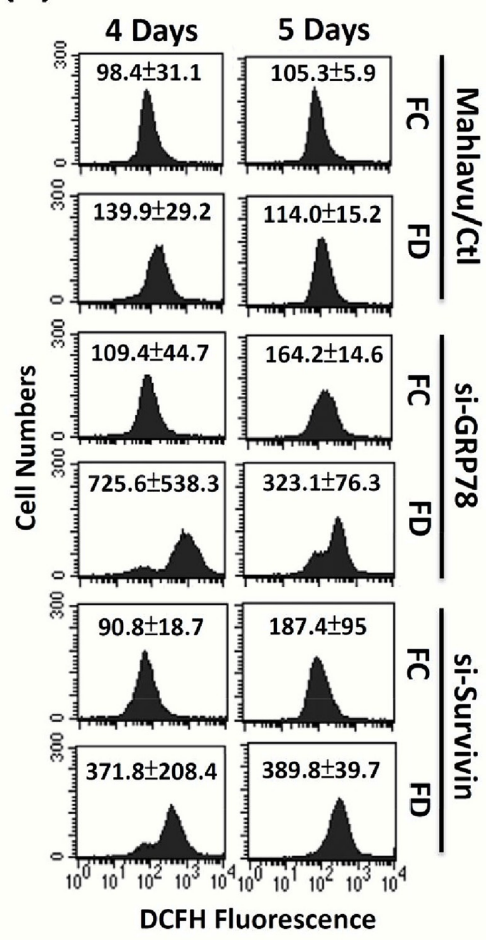

(E)

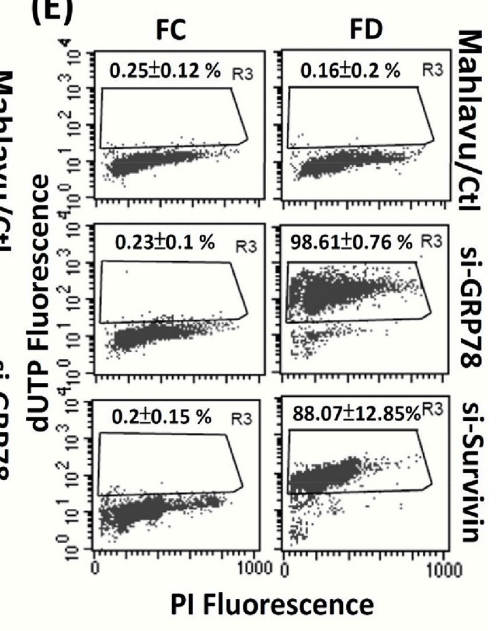

Figure 6: Evidence that either GRP78 or Survivin can confer Mahlavu cells the ability to evade from FD-induced apoptotic lethality. In order to delineate the possible role of GRP78 and Survivin in MDR acquisition, we generated GRP78 knockdown (si-GRP78) and Survivin knockdown (si-Survivin) cells using small interfering RNA technique A. First, we observed that Mahlavu cells with constitutively overexpressed GRP78 and Survivin were highly tolerable to FD-induced oxidative-nitrosative stress (ONS). However, both si-GRP78 and si-Survivin cells were shown to be extremely sensitive to FD-induced ONS-mediated cell death B and C. Further flowcytometric studies revealed that either GRP78 or Survivin alone could serve as ROS sinker via alleviating ROS generation and maintaining the integrity of mitochondrial membrane potential $(\Delta \Psi \mathrm{m})$ during an episode of FD condition D. Consequently, with the protection of either GRP78 or Survivin, Mahlavu cells could capacitate themselves to evade from FD-induced apoptotic lethality $\mathbf{E}$. 
(A)

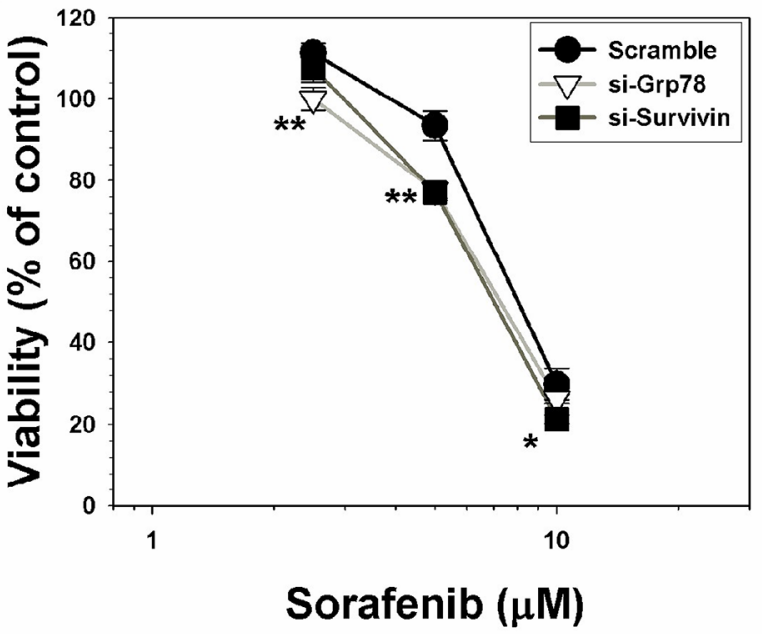

(C)

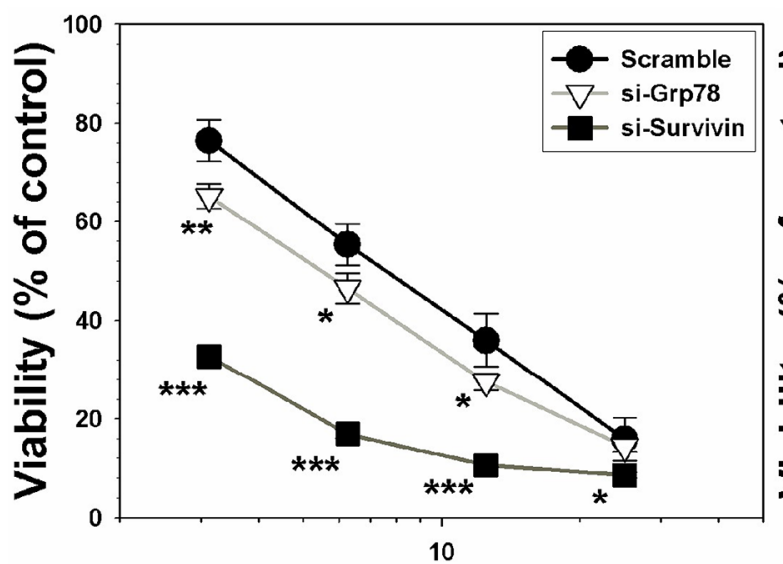

Paclitaxel (nM)
(B)

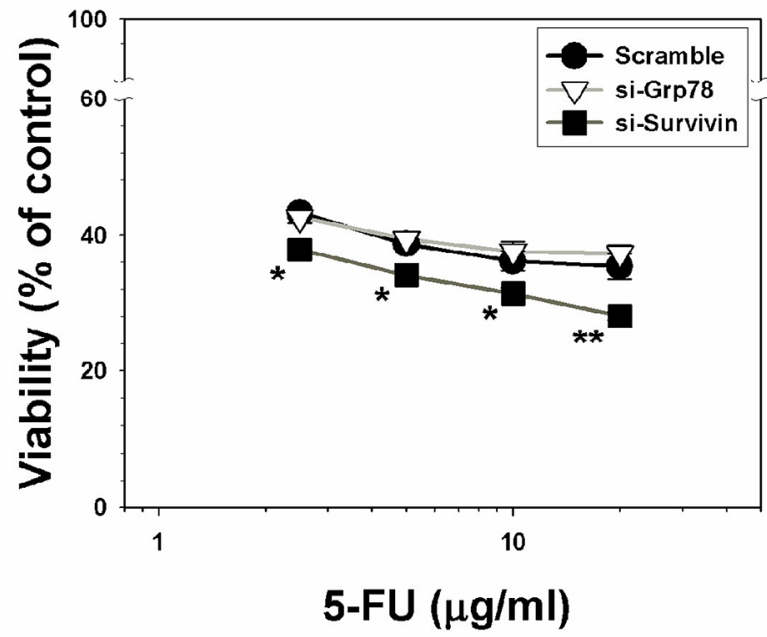

(D)

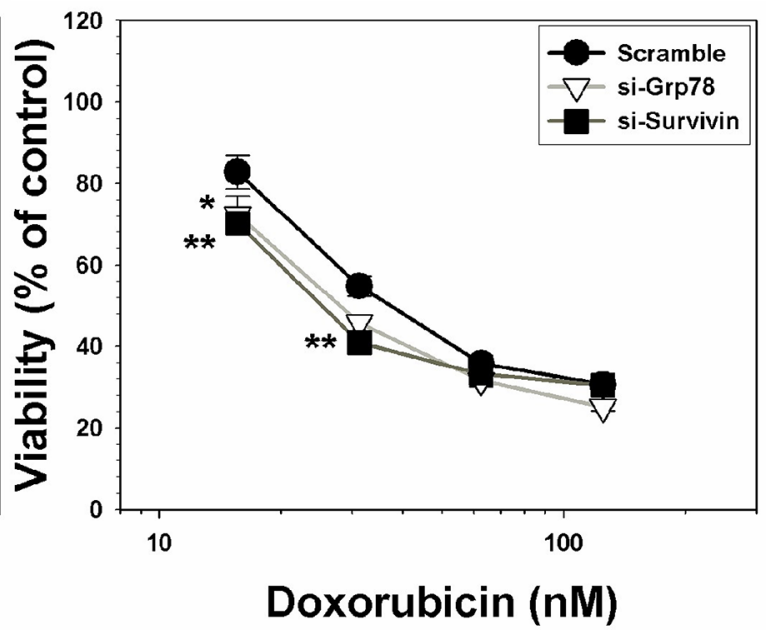

Figure 7: Silencing of genetically endowed GRP78 or Survivin alleviates MDR acquisition attribute of Mahlavu cells. Both GRP78 and Survivin of HCC Mahlavu cells were subjected to be knockdowned by siRNA technique. Subsequently, scramble, GRP78 KD and Survivin KD cells were treated with a group of anti-cancer drugs including sorafenib A. 5-FU B. paclitaxel C. and doxorubicin D. Our data indicate that without exception, all the drug-treated GRP78 KD or Survivin KD cells exhibited increased vulnerability to be eradicated by these drugs as compared to scramble cells indicating that both GRP78 and Survivin are genuine chemoresistant effectors. $* p<0.05 ; * * p 0.01 ; * * * p<0.001$.

becoming MDR against a group of ROS-producing anti-cancer agents including doxorubicin, paclitaxel, cisplatin and sorafenib (Figure 1). Interestingly, this transient drug resistance can be overcome by supplementation of folate to the culture medium. This finding has important clinical application.

Next, we investigated mechanism(s) of survival under FD-induced ONS. Recent work showed that ROS can cause redox adaptation, survival under ROS stress and resistance to certain anti-cancer agents [26]. As shown by Landriscina et al. [25], one of mechanism is heat-shock protein (HSP) expression. Elevated HSP expression prevents spontaneous apoptosis and apoptosis caused by therapeutic agents. We hypothesized that FD-induced ONS activates HSP pathways that confers MDR. Indeed, we found that SK-Hep-1 cells, but not Hep G2 cells, unilaterally activate chaperone protein 78 (GRP78). GRP78 plays role in the ER-Ca ${ }^{2+}$ balance via transmembrane ER stress sensor and controls protein folding [29-31]. As a biomarker of unfolded protein response (UPR), GRP78 overexpression has been associated with chemoresistance in a variety of cancers including head and neck squamous carcinoma, glioma, melanoma, breast and hepatoma [32-36]. Resupplementation of folate can effectively downregulate GRP78 expression in SK-Hep-1 cells, indicating that 
folate can be used to overcome drug resistance by FD. This finding underscores the clinical significance of monitoring the folate status prior to the therapeutic intervention. Our data demonstrated that FD-induced ONS probably upregulates an ER stress-associated GRP78 pathway via an enhanced cleavage of ATF6 $\alpha(90 \mathrm{kDa})$ transcription factor to its active ATF6 $\alpha(50 \mathrm{kDa})$ subunit and nuclear translocation to release GRP78 from its conjugated complex (Figure 2). FD was also induced overexpression of Survivin, which could enable SK-Hep-1 cells to evade apoptosis by inhibiting caspase 3 activation (Figure 2C). Both GRP78 and Survivin could then cooperatively alleviate ROS production [24] (Figures 2D and 6B).

Our work can help to improve tumor response and patient survival. We hypothesized that agents capable of abrogating such adaptation mechanisms in combination with conventional chemotherapy should improve therapeutic outcomes. We first utilize (-)-Epigallocatechin gallate (EGCG), one of the major constituents of green tea [37-41]. GRP78 overexpressed SK-Hep-1 cells after cultivating under FD condition for 2-week could be re-sensitized by EGCG to be eradicated more efficaciously than control cells without GRP78 expression. To further confirm this notion, we utilized Mahlavu cell, which is genetically endowed with overexpressed GRP78. When both Mahlavu and SK-Hep-1, cultivated under folate sufficient (FC) condition, only GRP78-expressing Mahlavu cells were more susceptible to be eradicated by EGCG targeting strategy. Besides GRP78-targeting strategy, we also performed the knockdown study via small RNA interfering technique on forced GRP78 overexpression induced by growing SK-Hep-1 cells under FD condition. As indicated in Figure 3, GRP78 KD cells (si-GRP78-1352 and si-GRP78-1932) were extremely vulnerable to be eradicated by all four anti-cancer drugs tested when compared to the scramble cells. Both GRP78 targeting strategy and Grp78 knockdown studies demonstrate that Grp78 is a contributing factor for MDR.

To test the universality of this finding, we thus set out to evaluate the relative sensitivity of two types of GRP78-overexpressing subclones (Mahlavu and Hep J5) and SK-Hep-1 (Grp78-nonexpressing subclone) cells toward a group of ROS-producing anti-cancer drugs including doxorubicin, 5-fluorouracil and sorafenib. Our data showed that indeed GRP78 plays a pivotal role in MDR acquisition because SK-Hep-1 cells were relatively more vulnerable to be eradicated by these ROS-producing anti-cancer drugs owing to the deficiency of GRP78 expression (Figure 5). In summary, GRP78, either constitutively endowed or forcedly expressed, could indeed contribute to the survival by defending exogenously ROS insults.

To further obtain evidence to substantiate the mechanistic link between GRP78, Survivin and MDR, we performed GRP78 and Survivin silencing experiment using siRNA technique. There are two important findings.
First, either GRP78 or Survivin silencing result in downregulation of heavy subunit of $\gamma$-glutamylcysteine synthetase $\left(\gamma-\mathrm{GCS}_{\mathrm{h}}\right)$, a critical catalytic enzyme responsible for the biosynthesis of GSH. Second, either GRP78 or Survivin silencing could drastically promote the production of ROS under FD condition as reflected by an approximately 3- to 6-fold increases in DCF fluorescence intensity observed flowcytometrically (Figure 6B). This finding implicates that both GRP78 and/or Survivin may play pivotal role as a ROS sinker. Consequently, elevated ROS production in cells without GRP78 or Survivin expression will ultimately provoke the depolarization of mitochondrial membrane potential $(\Delta \Psi \mathrm{m})$ leading to apoptotic lethality (Figure 6E). Along the same vein, either GRP78 or Survivin silencing could sensitize Mahlavu cells to be effectively eradicated by a group of ROS-producing anti-cancer drugs including sorafenib, 5-FU, paclitaxel and doxorubicin (Figure 7).

Several conclusions can be drawn from the current studies. First, our study adds to the literature on the direct and concrete evidence linking the relationship between FD-induced ONS and enhanced MDR acquisition. Second, our findings link FD-induced ROS to redox adaptation-mediated upregulation of GRP78 and Survivin. Third, disruption of GRP78 expression with EGCG and siRNA knockdown sensitized GRP78-expressing HCC cells to be eradicated. Fourth, our results suggest that prior to chemotherapeutic treatment, monitoring of nutritional status of folate probably should be necessary. In another words, treatment with folate to prevent its deficiency may be of critically importance to achieve satisfactory result of chemotherapy. Finally, the overall interactions of various pathways activated by FD-mediated ONS, which confer MDR, can be summarized diagrammatically in Figure 8.

\section{MATERIALS AND METHODS}

\section{Materials}

Folate, amino acids, nucleosides, nucleotides and other chemical compounds were purchased from Sigma-Aldrich (St. Louis, MO, USA). Minimal essential medium/alpha modified ( $\alpha$ MEM) without ribosides, ribotides, deoxyriboside, deoxyribotides, glycine, serine and folate was specially ordered and formulated by Invitogen and JRH (Lenexa, KS, USA). Fetal bovine serum (FBS) was from Biological Industries (Kibbutz, Israel). Penicillin, streptomycin, fungizone, trypsin and trypan blue were from GIBCO Laboratories (Grand Island, NY, USA).

Antibodies specific for heavy subunit of $\gamma$-glutamylcysteine synthetase $\left(\gamma-\mathrm{GCS}_{\mathrm{h}}\right), \mathrm{COX}-2, \mathrm{Bcl}-2$, GRP78, ATF4, ATF6 $\alpha$, SP-1 (Santa Cruz Biotechnology, california, USA), Survivin, pro-caspase 3 (Cell Signaling 


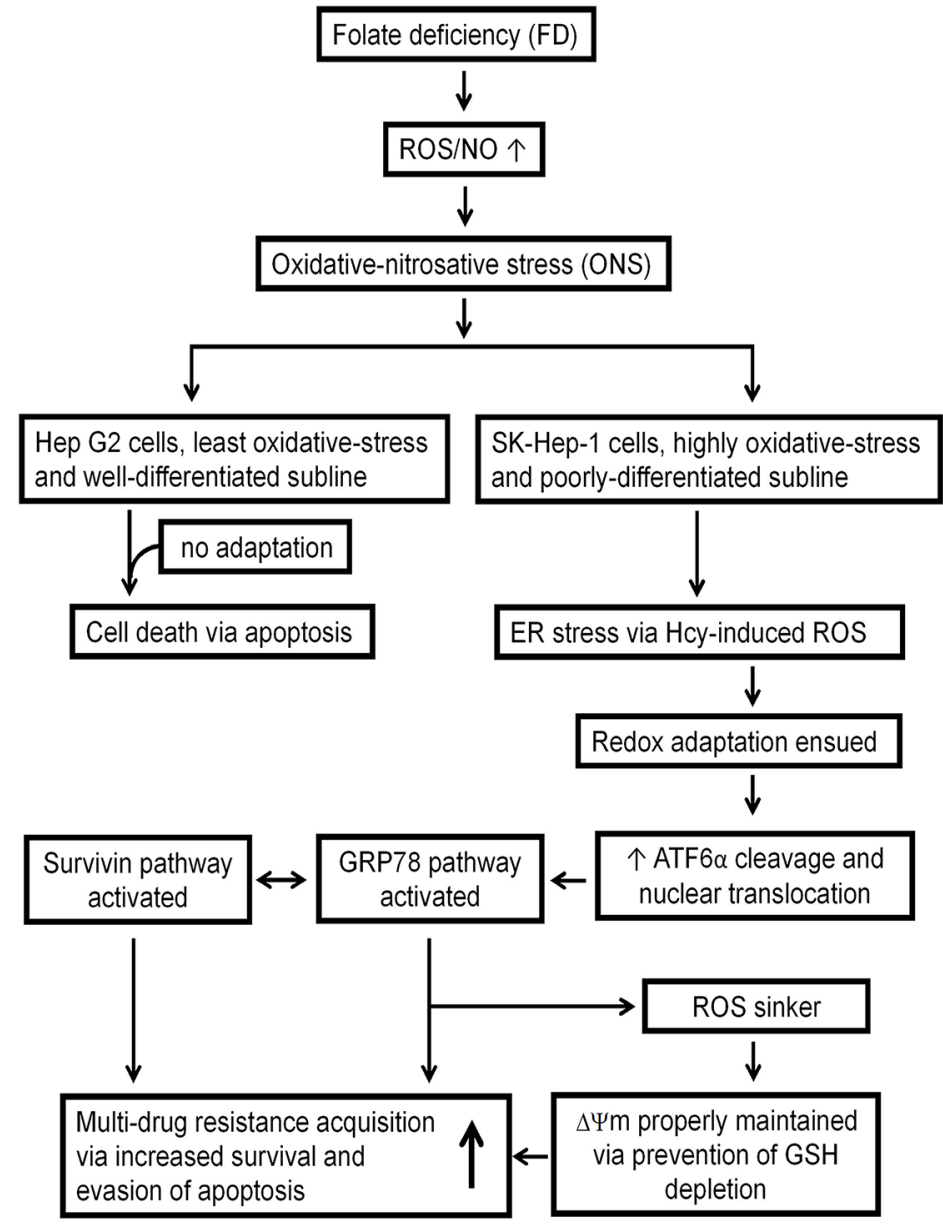

Figure 8: Diagrammatic representation illustrating the involvement of various pathways activated by FD-mediated ONS that conferring MDR attribute.

Technology, Danvers, MA, USA), PARP-1, $\beta$-catenin (Epitomics, california, USA), and $\beta$-actin (Sigma-Aldrich, St. Louis, MO, USA) were obtained.

\section{Cell line and cell culture}

Human hepatocellular carcinoma (HCC) cells were obtained from the National Development Center for Biotechnology (Taipei, Taiwan). A panel of 4 HCC cells, including Hep G2, SK-Hep-1, Hep J5 and Mahlavu, with distinct disparity in differentiation status were used as the experimental cell models. Cells was grown in minimal essential medium/alpha modified ( $\alpha \mathrm{MEM}$ ) with $10 \%$ heat-inactivated FBS and cultured at $37^{\circ} \mathrm{C}$ in a humidified atmosphere with $5 \% \mathrm{CO}_{2}$. $\alpha \mathrm{MEM}$ was complete medium contained with folate $(2 \mu \mathrm{mole} / \mathrm{L})$, thymidine $(36 \mu \mathrm{mole} / \mathrm{L})$, hypoxanthine $(36 \mu \mathrm{mole} / \mathrm{L})$, glycine $(600 \mu \mathrm{mole} / \mathrm{L})$, serine $(250 \mu \mathrm{mole} / \mathrm{L})$. Pencillin (20,000 units/L), streptomycin (20 mg/L) and fungizone $(2.5 \mathrm{mg} / \mathrm{L})$ were also added to media for the elimination of contamination. To formulate folate-deficient media, folate as well as thymidine, hypoxanthine and glycine were omitted from complete media to stress substrate availability in one-carbon metabolism. To minimize exogenous folate sources, fetal bovine serum was replaced with dialyzed fetal bovine serum (dFBS), which had been dialyzed at $4^{\circ} \mathrm{C}$ for 16 -h against $6 \times 10$ volumes of sterile PBS. Control medium was complete medium with $10 \%$ FBS. Therefore, HCC cells culture in folatedepleted medium (in the absence of folate and thymidine, hypoxanthine, glycine and serine) are designated as folate-deficient cells (FD). HCC cells culture in the control medium are referred to as folate control cells (FC).

\section{Preparation of total protein and nuclear extracts}

$1 \times 10^{6}$ of HCC cells were seeded in 10-cm dishes and maintained at $37^{\circ} \mathrm{C}$ with $5 \% \mathrm{CO}_{2}$ for $48 \mathrm{~h}$. Wholecell lysates and nuclear extracts were collected from cells at $80 \%$ confluence. Adherent cells were scraped into $3 \mathrm{ml}$ of cold phosphate-buffered saline (PBS), pelleted by centrifugation, and resuspended in $100 \mu \mathrm{l}$ of total lysis buffer (Enzo, Lausen, Switzerland) with protease inhibitors and phosphatase inhibitors (SigmaAldrich, St. Louis, MO, USA). Cells were broken up by strong vortexing and incubated on ice for $10 \mathrm{~min}$; these steps were repeated three times. Then, cell lysates 
were centrifuged at $13,000 \mathrm{rpm}$ for $30 \mathrm{~min}$ at $4^{\circ} \mathrm{C}$. The supernatants were whole-cell protein extracts.

The nuclear isolation procedure was based on the manufacturer's instructions from the Nuclei EZ Prep Kit (Sigma-Aldrich, St. Louis, MO, USA). Adherent cells were scraped into $150 \mu \mathrm{l}$ of Nuclei EZ Lysis buffer, swollen by mild vortexing on ice for $5 \mathrm{~min}$, and then centrifuged at $1000 \mathrm{~g}$ for $10 \mathrm{~min}$ at $4^{\circ} \mathrm{C}$. Supernatants containing cytoplasmic extracts were stored at $-80^{\circ} \mathrm{C}$. The nuclear pellet was resuspended in $100 \mu$ of Nuclei EZ Lysis buffer with mild vortexing on ice for $5 \mathrm{~min}$ to wash the pellet and then centrifugation at $1000 \mathrm{~g}$ for $10 \mathrm{~min}$ at $4^{\circ} \mathrm{C}$. After removing the supernatant, the nuclear pellet was lysed with Nuclei EZ Storage buffer and triturated 5 10 times with a micropipette to help break up clumps of nuclei. The final nuclear extracts in storage buffer were stored at $-80^{\circ} \mathrm{C}$ or used for Western blot analysis.

\section{Western blot analysis}

Protein expression was analyzed with a specific antibody. Equal amounts of protein extract (40 $\mu \mathrm{g}$, nuclear or total extract) were boiled for $6 \mathrm{~min}$ in sample buffer [300 mM Tris-HCl (pH 6.8), 3.85\% DTT, 9\% sodium dodecylsulfate (SDS), 25\% glycerol, and $0.033 \%$ bromophenol blue], subjected to $8 \% \sim 12 \%$ SDS-polyacrylamide gel electrophoresis (PAGE), and transferred to polyvinylidene difluoride (PVDF) membranes (Millipore, Billerica, MA, USA). Membranes were probed with first antibodies against $\gamma-\operatorname{GCS}_{\mathrm{h}}(1: 500)$, actin (1: 10 $)$, COX-2 (1: 500), Bcl-2 (1: 250), GRP78 (1: 1000), ATF4 (1: 250), ATF6 $\alpha$ (1: 250), Survivin (1: 1000), pro-caspase 3 (1: 1000), PARP-1 (1: 1000), $\beta$-catenin (1: 1000) and SP-1 (1: 500). After washing in TBST buffer, the membrane was further incubated with anti-rabbit secondary antibody (Chemicon, Millipore, Billerica, MA, USA) for 1-h. Detection was performed by enhanced chemiluminescence (ECL; Millipore, Billerica, MA, USA) after incubation with a horseradish peroxidase (HRP)-conjugated secondary antibody. $\beta$-actin was used as the loading control.

\section{Cell viability assay}

Cells were seeded in a 6-well plastic plate and exposed to 1, $5 \mu \mathrm{M}$ doxorubicin (Sigma-Aldrich, St. Louis, MO, USA ), 20, $40 \mu \mathrm{g} / \mathrm{ml}$ cisplatin $\left(\right.$ Platinol $\left.^{\circledR}\right), 1,5 \mu \mathrm{g} / \mathrm{ml}$ paclitaxel $\left(\right.$ Taxol $\left.^{\circledR}\right), 20,40 \mu \mathrm{M}$ sorafenib $\left(\right.$ Nexavar $\left.^{\circledR}\right)$ in duplicate for 48-h in at least two independent experiments $(n=4)$. Cell viability was assayed by the sulforhodamine B (SRB) method. Growth inhibition was calculated as the percentage of surviving cells in drug-treated versus untreated cells (which were incubated with FD for 1 or 2 weeks). In SRB method, cultures fixed with trichloroacetic acid and were stained for 30 minutes with $0.4 \%$ (w/v) SRB (Sigma-Aldrich, St. Louis, MO, USA) dissolved in 1\% acetic acid. Unbound dye was removed by two washes with $1 \%$ acetic acid, and protein-bound dye was extracted with $10 \mathrm{mM}$ unbuffered Tris base [tris(hydroxymethyl) aminomethane] for determination of optical density in 515 or $540 \mathrm{~nm}$ by ELISA reader.

\section{Lentivirus-mediated knockdown of GRP78 expression}

Small hairpin RNA (shRNA) targeting HSPA5 (GRP78) (si-GRP78-700: GCCATGGTTCTCACTAAAA, sh-GRP78-1352: GCTCGACTCGAATTCCAAA and si-GRP78-1932: GCGCATTGATACTAGAAAT) were cloned into the pLV-H1-EF1a-GFP-Puro vector and packaged in a lentivirus (Biosettia, USA). Lentivirus-containing medium and polybrene were added to cultures of folate deficiency-treated SK-Hep-1 cells with puromycin selection.

\section{Generation of GRP78 or survivin knockdown mahlavu cells}

The GRP78 and Survivin knockdown of Mahlavu cells were carried out according to the procedures of Chang et al. [23, 24]. Briefly, the target sequence for the human GRP78 mRNA was 5'-AAGGTTACCCATGCAGTTGTT-3' and the human Survivin mRNA was 5'-TGGGAGCCA GATGACGACC-3'. The scrambled siRNA sequence was 5'-AAGGTGGTTGTTTTGTTCACT-3'. The GRP78 siRNA, Survivin siRNA and scrambled siRNA were inserted into the pSUPERIOR vector and transfected into the cells. We applied 1 pulse for 20 milliseconds under a fixed voltage of $1.4 \mathrm{kV}$ on a pipette-type microporator Neon (Invitrogen Life Technologies). Cells that were successfully transfected were selected by antibiotic resistance.

\section{Flowcytometric measurement of intracellular ROS and mitochondrial membrane potential $(\triangle \Psi \mathbf{m})$}

All fluorescence probes were purchased from Sigma-Aldrich (St. Louis, MO) unless otherwise specified. Intracellular ROS production was measured using DCFH-DA probe. Briefly after cells were cultivated under FD condition, the culture medium was then replaced with new FD medium and followed by the incubation with $10 \mu \mathrm{M}$ DCFH-DA for $30 \mathrm{~min}$ in the dark. Cells were then washed once with PBS, detached by trypsinization and collected by centrifugation and re-suspended in PBS.

To measure cellular mitochondrial membrane potential $(\Delta \Psi \mathrm{m}), \mathrm{FC}$ or FD cells were incubated with $5 \mu \mathrm{M}$ rhodamine 123 for $30 \mathrm{~min}$ in the dark. Cells were then washed twice with PBS, detached by trypsinization and collected by centrifugation and re-suspended in PBS. The fluorescence intensity was measured using a 
FACS-Calibur flowcytometer (BD Biosciences, San Jose, CA) and analyzed using CellQuest software.

\section{TUNEL assay}

Apoptotic cell death was assayed by using an Apo-BrdU in situ DNA fragmentation assay kit (Promega, Medison, WI, USA). This kit measures the fragmented DNA of apoptotic cells by catalytically incorporating fluorescein-12-dUTP at 3'-OH DNA ends using the terminal deoxynucleotidyl transferase enzyme. The fluorescein-12-dUTP-labeled DNA can then be quantitiated by flowcytometry. In this study, Mahlavu cells were cultivated in either FC or FD condition for six days and the fluoressein-12-dUTP-labeled fragmented DNA of apoptotic cells were quantified using Becton-Dickinson FACS-Calibur flow- cytometer.

\section{Statistical analysis}

Data were expressed as the mean \pm standard deviation (SD) from at least two independent experiments. A paired Student's $t$-test was used to determine the differences between control and treatment groups (Sigma plot 8.0 software). Differences at a level of $p<0.05$ for Student's $t$-test were considered statistically significant.

\section{ACKNOWLEDGMENTS}

The expert technical assistance of professor Yu-Jia Chang and Ruo-Chiou Wang is greatly appreciated.

\section{CONFLICTS OF INTEREST}

The authors declare no conflict of interest.

\section{Author contributions}

Conceived and designed the experiments: Hung-Sheng Shang, Jun-Jen Liu and Tsan-Zon Liu; Performed the experiments: Chun-Te Ho, Hung-Sheng Shang; Analyzed the data: Jin-Biou Chang, Jun-Jen Liu, Chun-Te Ho; Contributed reagents/materials/analysis tools: Jun-Jen Liu and Jin-Biou Chang. Wrote the paper: Tsan-Zon Liu. Provided important feedback on data analysis, contributed to discussion and reviewed the manuscript: Chun-Te Ho and Jun-Jen Liu.

\section{REFERENCES}

1. Strickland KC, Krupenko NI, Krupenko SA. Molecular mechanisms underlying the potentially adverse effects of folate. Clinical chemistry and laboratory medicine: CCLM / FESCC. 2013; 51:607-616.
2. Stover PJ. Physiology of folate and vitamin B12 in health and disease. Nutrition reviews. 2004; 62:S3-12. discussion S13.

3. Lemos C, Kathmann I, Giovannetti E, Belien JA, Scheffer GL, Calhau C, Jansen G, Peters GJ. Cellular folate status modulates the expression of BCRP and MRP multidrug transporters in cancer cell lines from different origins. Molecular cancer therapeutics. 2009; 8:655-664.

4. Weitman SD, Weinberg AG, Coney LR, Zurawski VR, Jennings DS, Kamen BA. Cellular localization of the folate receptor: potential role in drug toxicity and folate homeostasis. Cancer research. 1992; 52:6708-6711.

5. Ross JF, Chaudhuri PK, Ratnam M. Differential regulation of folate receptor isoforms in normal and malignant tissues in vivo and in established cell lines. Physiologic and clinical implications. Cancer. 1994; 73:2432-2443.

6. Parker N, Turk MJ, Westrick E, Lewis JD, Low PS, Leamon CP. Folate receptor expression in carcinomas and normal tissues determined by a quantitative radioligand binding assay. Analytical biochemistry. 2005; 338:284-293.

7. Low PS, Kularatne SA. Folate-targeted therapeutic and imaging agents for cancer. Current opinion in chemical biology. 2009; 13:256-262.

8. Mukherjee S, Ghosh S, Choudhury S, Adhikary A, Manna K, Dey S, Sa G, Das T, Chattopadhyay S. Pomegranate reverses methotrexate-induced oxidative stress and apoptosis in hepatocytes by modulating Nrf2-NF-kappaB pathways. The Journal of nutritional biochemistry. 2013; 24:2040-2050.

9. Sener G, Eksioglu-Demiralp E, Cetiner M, Ercan F, Sirvanci S, Gedik N, Yegen BC. L-Carnitine ameliorates methotrexate-induced oxidative organ injury and inhibits leukocyte death. Cell biology and toxicology. 2006; 22:47-60.

10. Siegel R, Ma J, Zou Z, Jemal A. Cancer statistics. CA: a cancer journal for clinicians. 2014; 64:9-29.

11. Tabrizian P, Roayaie S, Schwartz ME. Current management of hepatocellular carcinoma. World journal of gastroenterology: WJG. 2014; 20:10223-10237.

12. Llovet JM, Ricci S, Mazzaferro V, Hilgard P, Gane E, Blanc JF, de Oliveira AC, Santoro A, Raoul JL, Forner A, Schwartz M, Porta C, Zeuzem S, Bolondi L, Greten TF, Galle PR, et al. Sorafenib in advanced hepatocellular carcinoma. The New England journal of medicine. 2008; 359:378-390.

13. Welzel TM, Katki HA, Sakoda LC, Evans AA, London WT, Chen G, O'Broin S, Shen FM, Lin WY, McGlynn KA. Blood folate levels and risk of liver damage and hepatocellular carcinoma in a prospective high-risk cohort. Cancer epidemiology, biomarkers \& prevention: a publication of the American Association for 
Cancer Research, cosponsored by the American Society of Preventive Oncology. 2007; 16:1279-1282.

14. Lin CC, Yin MC. B vitamins deficiency and decreased anti-oxidative state in patients with liver cancer. European journal of nutrition. 2007; 46:293-299.

15. Kuo CS, Lin CY, Wu MY, Lu CL, Huang RF. Relationship between folate status and tumour progression in patients with hepatocellular carcinoma. The British journal of nutrition. 2008; 100:596-602.

16. Meenan J, O'Hallinan E, Scott J, Weir DG. Epithelial cell folate depletion occurs in neoplastic but not adjacent normal colon mucosa. Gastroenterology. 1997; 112:1163-1168.

17. Pogribny IP, James SJ, Beland FA. Molecular alterations in hepatocarcinogenesis induced by dietary methyl deficiency. Molecular nutrition \& food research. 2012; 56:116-125.

18. Chern CL, Huang RF, Chen YH, Cheng JT, Liu TZ. Folate deficiency-induced oxidative stress and apoptosis are mediated via homocysteine-dependent overproduction of hydrogen peroxide and enhanced activation of NF-kappaB in human Hep G2 cells. Biomedicine \& pharmacotherapy $=$ Biomedecine $\&$ pharmacotherapie. 2001; 55:434-442.

19. James SJ, Pogribny IP, Pogribna M, Miller BJ, Jernigan S, Melnyk S. Mechanisms of DNA damage, DNA hypomethylation, and tumor progression in the folate/methyl-deficient rat model of hepatocarcinogenesis. The Journal of nutrition. 2003; 133:3740S-3747S.

20. Lim J, Lee SH, Cho S, Lee IS, Kang BY, Choi HJ. 4-methoxychalcone enhances cisplatin-induced oxidative stress and cytotoxicity by inhibiting the Nrf2/ARE-mediated defense mechanism in A549 lung cancer cells. Molecules and cells. 2013; 36:340-346.

21. Chiou JF, Tai CJ, Wang YH, Liu TZ, Jen YM, Shiau CY. Sorafenib induces preferential apoptotic killing of a drug- and radio-resistant Hep G2 cells through a mitochondria-dependent oxidative stress mechanism. Cancer biology \& therapy. 2009; 8:1904-1913.

22. Coriat R, Nicco C, Chereau C, Mir O, Alexandre J, Ropert S, Weill B, Chaussade S, Goldwasser F, Batteux F. Sorafenib-induced hepatocellular carcinoma cell death depends on reactive oxygen species production in vitro and in vivo. Molecular cancer therapeutics. 2012; 11:2284-2293.

23. Wei PL, Kuo LJ, Wang W, Lin FY, Liu HH, How T, Ho YS, Huang MT, Wu CH, Chang YJ. Silencing of glucose-regulated protein 78 (GRP78) enhances cell migration through the upregulation of vimentin in hepatocellular carcinoma cells. Annals of surgical oncology. 2012; 19:S572-579.

24. Tai CJ, Chin-Sheng H, Kuo LJ, Wei PL, Lu HH, Chen HA, Liu TZ, Liu JJ, Liu DZ, Ho YS, Wu CH, Chang YJ. Survivin-mediated cancer cell migration through GRP78 and epithelial-mesenchymal transition (EMT) marker expression in Mahlavu cells. Annals of surgical oncology. 2012; 19:336-343.

25. Landriscina M, Maddalena F, Laudiero G, Esposito F. Adaptation to oxidative stress, chemoresistance, and cell survival. Antioxidants \& redox signaling. 2009; 11:2701-2716.

26. Trachootham D, Alexandre J, Huang P. Targeting cancer cells by ROS-mediated mechanisms: a radical therapeutic approach? Nature reviews Drug discovery. 2009; 8:579-591.

27. Huang RF, Ho YH, Lin HL, Wei JS, Liu TZ. Folate deficiency induces a cell cycle-specific apoptosis in HepG2 cells. The Journal of nutrition. 1999; 129:25-31.

28. Huang RF, Huang SM, Lin BS, Wei JS, Liu TZ. Homocysteine thiolactone induces apoptotic DNA damage mediated by increased intracellular hydrogen peroxide and caspase 3 activation in HL-60 cells. Life sciences. 2001; 68:2799-2811.

29. Kozutsumi Y, Segal M, Normington K, Gething MJ, Sambrook J. The presence of malfolded proteins in the endoplasmic reticulum signals the induction of glucose-regulated proteins. Nature. 1988; 332:462-464.

30. Ni M, Lee AS. ER chaperones in mammalian development and human diseases. FEBS letters. 2007; 581:3641-3651.

31. Schroder M, Kaufman RJ. The mammalian unfolded protein response. Annual review of biochemistry. 2005; 74:739-789.

32. Ranganathan AC, Zhang L, Adam AP, Aguirre-Ghiso JA. Functional coupling of $\mathrm{p} 38$-induced up-regulation of BiP and activation of RNA-dependent protein kinase-like endoplasmic reticulum kinase to drug resistance of dormant carcinoma cells. Cancer research. 2006; 66:1702-1711.

33. Pyrko P, Schonthal AH, Hofman FM, Chen TC, Lee AS. The unfolded protein response regulator GRP78/BiP as a novel target for increasing chemosensitivity in malignant gliomas. Cancer research. 2007; 67:9809-9816.

34. Jiang CC, Mao ZG, Avery-Kiejda KA, Wade M, Hersey P, Zhang XD. Glucose-regulated protein 78 antagonizes cisplatin and adriamycin in human melanoma cells. Carcinogenesis. 2009; 30:197-204.

35. Grkovic S, O'Reilly VC, Han S, Hong M, Baxter RC, Firth SM. IGFBP-3 binds GRP78, stimulates autophagy and promotes the survival of breast cancer cells exposed to adverse microenvironments. Oncogene. 2013; 32:2412-2420.

36. Tang J, Guo YS, Zhang Y, Yu XL, Li L, Huang W, Li Y, Chen B, Jiang JL, Chen ZN. CD147 induces UPR to inhibit apoptosis and chemosensitivity by increasing the transcription of Bip in hepatocellular carcinoma. Cell death and differentiation. 2012; 19:1779-1790. 
37. Ermakova SP, Kang BS, Choi BY, Choi HS, Schuster TF, Ma WY, Bode AM, Dong Z. (-)-Epigallocatechin gallate overcomes resistance to etoposide-induced cell death by targeting the molecular chaperone glucose-regulated protein 78. Cancer research. 2006; 66:9260-9269.

38. Li M, Wang J, Jing J, Hua H, Luo T, Xu L, Wang R, Liu D, Jiang Y. Synergistic promotion of breast cancer cells death by targeting molecular chaperone GRP78 and heat shock protein 70 . Journal of cellular and molecular medicine. 2009; 13:4540-4550.

39. Luo T, Wang J, Yin Y, Hua H, Jing J, Sun X, Li M, Zhang Y, Jiang Y. (-)-Epigallocatechin gallate sensitizes breast cancer cells to paclitaxel in a murine model of breast carcinoma. Breast cancer research: BCR. 2010; 12:R8.

40. Wang J, Yin Y, Hua H, Li M, Luo T, Xu L, Wang R, Liu D, Zhang Y, Jiang Y. Blockade of GRP78 sensitizes breast cancer cells to microtubules-interfering agents that induce the unfolded protein response. Journal of cellular and molecular medicine. 2009; 13:3888-3897.

41. Wu PP, Kuo SC, Huang WW, Yang JS, Lai KC, Chen HJ, Lin KL, Chiu YJ, Huang LJ, Chung JG. (-)-Epigallocatechin gallate induced apoptosis in human adrenal cancer NCI-H5 cells through caspase-dependent and caspase-independent pathway. Anticancer research. 2009; 29:1435-1442. 